\title{
FEMINISME \\ DALAM PERGELARAN WAYANG KULIT PURWA TOKOH DEWI SHINTA, DEWI KUNTI, DEWI SRIKANDI
}

\section{Iva Ariani}

Fakultas Filsafat Universitas Gadjah Mada

Email: iva.ariani@yahoo.co.id

\begin{abstract}
Abstrak
Penelitian ini adalah penelitian kualitatif dengan tujuan untuk memahami secara lebih mendalam kedudukan hakiki perempuan dalam budaya Jawa melalui cerita dalam pagelaran wayang kulit purwa dan memperoleh pemahaman tentang nilai-nilai feminism dalam wayang kulit purwa dan relevansinya bagi kehidupan perempuan di Jawa. Hasil penelitian ini menunjukkan bahwa pagelaran wayang kulit purwa adalah suatu karya seni fenomenal yang memiliki kisah-kisah yang dapat dijadikan gambaran bagi kehidupan manusia. Nilainilai feminisme yang diajarkan dalam pagelaran wayang kulit di antaranya adalah bahwa perempuan dalam wayang yang digambarkan dalam tokoh Dewi Shinta, Srikandi dan Dewi Kunti adalah sikap bakti dan hormat pada suami baik dalam suka maupun duka, setia dan taat pada suami meskipun harus dimadu, selalu menjaga kesucian, religious, dan terampil membela suami dalam kesulitan. Nilai-nilai tersebut banyak digunakan sebagai ajaran dalam kehidupan perempuan di Jawa yang memegang teguh nilai-nilai kesetiaan terhadap suamidan sabar dan ikhlas menjalani hidup dan kehidupan.
\end{abstract}

Kata kunci: feminisme, pergelaran wayang kulit, kesetiaan.

\section{Abstract}

This research is a qualitative research which aims to understand the real position of woman in Javanesse culture based on the story of shadow puppets (wayang kulit purwa) performance and to know the values of feminism which relevant with the a woman's life in Java. The results of this study indicate that shadow puppet purwa is a phenomenal piece of art that have stories that can be used as a metaphor for human life. The values of feminism taught in shadow puppet which is that women in puppets depicted in figure Dewi Shinta, Srikandi and Kunti are the attitude of devotion and respect for her husband both in joy and sorrow, loyal and obedient to her husband though it should be a co-wife, always 
maintain purity, religious, and skilled defending her husband in trouble. Those values are widely used as the teaching of women's lives in Java that uphold the values of loyalty towards her husband and patience and sincerity live and life. Key words: feminism, shadow puppet performance, faithfulness.

\section{PENDAHULUAN}

Indonesia merupakan negara yang kaya akan budaya. Sebagai sebuah negara kepulauan, kebudayaan-kebudayaan yang ada di Indonesia menjadi sangat beragam. Salah satu dari sekian banyak karya seni yang ada adalah wayang. Wayang merupakan hasil cipta, rasa dan karsa manusia Indonesia karena proses spiritual. Wayang kulit purwa menurut perkembangannya bukan hanya merupakan tontonan semata, namun juga merupakan tuntunan bagi penonton dan penikmatnya. Wayang kulit purwa banyak mengajarkan nilai-nilai luhur yang adiluhung tidak hanya nilai-nilai kejuangan, namun juga nilai-nilai feminis.

Emansipasi wanita, sering dinisbatkan menjadi gerakan tuntutan agar kaum perempuan bisa masuk ke bidang-bidang yang diminati sama dengan pria bahkan tak jarang, sampai masuk ke wilayah agama yang sudah jelas dasar dan ketentuannya. Feminisme akhirnya menjadi global theology (agama global). Hal seperti ini tentunya memunculkan banyak kekhawatiran yang mendalam dalam masyarakat Indonesia terutama pemuka agama dan tokoh adat sehingga diperlukan suatu reinterpretasi tentang emansipasi dan niai-nilai feminisme yang sesuai dengan latar belakang budaya masyarakat Indonesia.

Diskriminasi gender yang sering muncul akhir-akhir ini mengakibatkan perempuan semakin tereksploitasi dan diperlakukan tidak adil. Perempuan diwajibkan memainkan tiga peran sekaligus, yaitu peran produktif, mengelola rumah tangga, dan menjalin hubungan dengan masyarakat. Adanya peran perempuan seperti tersebut di atas, peran laki-laki di bidang produksi akan semakin tinggi dan mengakibatkan sifat ingin berkuasanya laki-laki akan semakin besar. Perempuan, dalam kehidupan sehari-hari seolah-olah ditakdirkan untuk menjadi abdi dan pelayan suami dalam segala hal, sedangkan segala 
keputusan ada di tangan laki-laki. Ketidakberesan dalam urusan rumah tangga pun selalu dilimpahkan kepada kesalahan sang istri.

Ketimpangan gender seperti tersebut di atas mengakibatkan pandangan masyarakat terhadap pekerjaan rumah tangga kaum perempuan menjadi rendah dibandingkan dengan pekerjaan yang dilakukan oleh kaum laki-laki. Sementara perempuan menerima saja apa adanya akan peran gender mereka, dan laki-laki tidak diwajibkan bekerja di bidang domestik. Semua itu telah dilanggengkan berdasarkan budaya yang sudah ada (Faqih, 1987: 21). Anggapan seperti itu telah ada sejak dahulu, dan hal itu membuat setiap perempuan semakin takut untuk mencoba keluar dari peran gender mereka. Perempuan semakin pasrah dan diam kepada keputusan yang dibuat oleh laki-laki.

Bertolak dari persoalan tersebut, maka penulis menganggap perlu untuk kembali mengangkat persoalan-persoalan feminisme khususnya feminisme dalam cerita pergelaran wayang kulit purwa menjadi sesuatu yang dapat dijadikan bahan penelitian. Uraian-uraian tersebut di atas akan membawa pada persoalan-persoalan yang dapat dirumuskan sebagai berikut: bagaimanakah ajaran feminisme yang dimunculkan dalam pagelaran wayang kulit purwa?; bagaimanakah feminisme wayang berpengaruh dalam kehidupan perempuan di Jawa?

Penelitian ini adalah penelitian kualitatif dengan mengumpulkan data yang dikelompokkan menjadi data primer dan data sekunder. Data primer dari penelitian ini adalah data tentang kisah dan perjalanan hidup Dewi Shinta, Dewi Kunti, dan Dewi Srikandi yang didapat melalui kisah yang diceritakan dalang melalui pergelaran wayang kulit purwa dan dari buku-buku atau literatur yang menceritakan kisah dan perjalanan hidup Dewi Shinta, Dewi Kunti dan Dewi Srikandi.

Penelitian ini dilakukan dengan cara peneliti melihat dan mempelajari cerita-cerita dalam pagelaran wayang kulit purwa yang mengisahkan tentang perjalanan hidup seorang wanita yaitu Shinta dalam Ramayana, Kunti dalam Mahabharata dan Srikandi dalam Bharatayudha. Penulis kemudian melakukan proses pengumpulan data berkaitan dengan feminisme dalam cerita wayang kulit purwa. Pengum- 
pulan data dilakukan dengan cara melakukan wawancara dengan tokoh-tokoh yang ahli dalam pedalangan dan melakukan kajian melalui studi pustaka.

Data yang terkumpul kemudian dianalisis dengan menggunakan metode interpretasi dan hermeneutika untuk mendapatkan konsep yang jelas tentang nilai-nilai feminisme dalam cerita wayang kulit purwa yang selanjutnya disusun dalam sebuah tulisan yang komprehensif. Harapannya, tulisan ini dapat dipergunakan sebagai masukan bagi perkembangan gerakan-gerakan perempuan di Indonesia.

\section{SEKILAS TENTANG FEMINISME}

Studi gender menguraikan bahwa terdapat berbagai bentuk ketidakadilan seperti adanya pemiskinan ekonomi terhadap perempuan, subordinasi pada salah satu jenis kelamin, pelabelan negative (stereotip) pada jenis kelamin tertentu, kekerasan terhadap perempuan dan peran gender perempuan adalah mengelola rumah tangga (Faqih, 1987: 72). Melihat adanya studi gender tersebut menunjukkan bahwa manusia yang berjenis kelamin laki-laki belum memahami harkat dan martabat perempuan. Hal ini ditunjang pula oleh suatu kemajuan teknologi yang mendominasi laki-laki di dalamnya.

Filsafat feminis dapat dikatakan merupakan cara berpikir yang menekankan pengalaman, identitas, serta cara berada dan berpikir perempuan dilihat sama seperti kaum pria. Singkatnya, bagaimana berfilsafat dari sudut pandang perempuan. Menurut para filsuf feminis, gagasan mendasar mengenai Tuhan, dunia dan manusia dibangun atas dasar konsep patriarkal (dari bahasa Latin, pater: bapa). Akibatnya, peranan perempuan kurang diperlihatkan bahkan tidak jarang dirugikan. Peranan dan perjuangan perempuan justru dikuasai dan diukur dari konsep patriarkal. Para filsuf feminis, oleh karenanya, bermaksud merombak kembali gagasan-gagasan mendasar yang menjadikan perempuan berkedudukan seperti itu.

Perjuangan kesetaraan dan keadilan gender telah berlangsung cukup lama. Terbentang cukup jauh, sebelum Indonesia menyatakan 
kemerdekaannya hingga era reformasi ini. Tokoh-tokohnya pun cukup beragam. Begitu juga menyangkut isu yang diusung. Gerakan perempuan di Indonesia namun demikian, mulai menyeruak ke permukaan setelah terbit buku kompilasi surat-menyurat Kartini dengan temanteman Belandanya (Ny. Abendanon, Stella, Ny. Ovink-Soer, dll) bertajuk Door Duisternis Tot Licht (1911). Buku ini menjadi populer ketika Armin Pane, pujangga angkatan Balai Pustaka, menerjemahkannya dan memberinya judul Habis Gelap Terbitlah Terang. Buku ini dianggap memberi inspirasi bagi kaum wanita di Indonesia untuk memperjuangkan harkat dan martabatnya agar sejajar dengan laki-laki. Alhasil kata "emansipasi wanita" menjadi kata-kata yang sangat familiar di negeri ini; dan Kartini pun didaulat sebagai salah seorang pahlawan wanita kebanggaan bangsa ini.

Kartini, dalam surat-suratnya, bercerita tentang kegetiran dan nestapa yang dialaminya sebagai anak-wanita seorang priyayi Jawa (Bupati). Ia selalu ditempatkan sebagai makhluk kelas dua setelah saudara laki-lakinya. Perannya dianggap lebih rendah dibandingkan laki-laki. Atas pengalaman yang dialaminya itu, Kartini sampai pada kesimpulan bahwa wanita Indonesia harus bergerak dan bangkit melawan penindasan ini. Untuk bangkit itu, "Kartini bercita-cita memberi bekal pendidikan kepada anak-anak perempuan, terutama budi pekerti, agar mereka menjadi ibu yang berbudi luhur, yang dapat berdiri sendiri mencari nafkah sehingga mereka tidak perlu kawin kalau mereka tidak mau." (Sutrisno, 1985: xvii).

Budaya Jawa juga sering menempatkan perempuan seolah-olah menjadi nomor dua. Perempuan Jawa tidak ditempatkan pada kedudukan yang setara dengan laki-laki. Perempuan, namun demikian tetap memberikan sifat-sifat atau cirri yang terhormat, antara lain kesetiaan, kepatuhan, kesabaran, dan kemampuan untuk menyembunyikan gejolak batin. Sederet ciri atau sifat kebaikan itu bukan hanya diberikan kepada tokoh perempuan dari kalangan ningrat saja tetapi juga kepada mereka yang berasal dari kalangan rakyat jelata (Sarjono, 1992: 45). 
Perempuan jawa yang masih keturunan ningrat selalu berusaha menempatkan kebahagiaan pada kehidupan perkawinannya. Di sini ada semacam identifikasi diri dengan suaminya. Bahkan semacam peleburan diri. Kebahagiaan suami adalah kebahagiaan dirinya. Bahkan sedemikian kuatnya anggapan itu sehingga semua istri dari golongan priyayi selalu berusaha sekuat tenaga untuk membahagiakan suami dengan berbagai cara (Sarjono, 1992: 49). Hal tersebut tentu saja juga terjadi dalam kehidupan seksualitas dalam arti pihak perempuan selalu mengalah dan menjadi nomor dua untuk membahagiakan pasangannya.

Perempuan dalam kehidupannya sebagai manusia pada dasarnya memiliki kedudukan yang sama dengan laki-laki. Secara kodrati manusia mempunyai dua kedudukan yaitu pribadi mandiri dan makhluk Tuhan sekaligus (Notonagoro, 1968: 98). Pribadi mandiri, dalam aktivitas kehidupan sosialnya lebih diwakili oleh sosok laki-laki yang memang memiliki sifat kemandirian yang lebih tinggi daripada perempuan, dan perempuan mewakili sosok mahkluk Tuhan yang lebih mengedepankan unsur ragawinya.

Sebagai realitas yang bercahaya di luar jiwa, ruh adalah seorang ayah, sebab semua sifat positif berasal darinya. Sebaliknya jiwa yang terwujud adalah seorang ibu, sebab ia merupakan lokus tempat sifatsifat ruh terwujud (Murata, 1999: 198).

Persamaan kodrat antara laki-laki dan perempuan juga nyata dijelaskan dalam pandangan yang menyatakan bahwa sebenarnya kisah Adam dan Hawa adalah proyeksi dari esensi dan eksistensi, yang semula memang "identik", "sama", dekat dalam suasana yang surgawi (Supadjar, 1993: 178).

Perempuan Jawa dalam kehidupannya, terbiasa dengan didikan untuk selalu mengalah. Seorang istri, dalam kehidupan rumah tangga tidak mungkin bisa memiliki suaminya secara penuh. Seorang suami, dalam lingkup kehidupan sejak ia lahir, tidak memberikan cinta hanya kepada seorang perempuan saja. Dunia permaduan dan perseliran sudah terbiasa dilihatnya, harus diterimanya sebagai suatu kenyataan 
yang harus diterima meskipun itu cinta yang separuh dari suaminya (Sardjono, 1992: 45).

\section{TOKOH PEREMPUAN}

\section{DALAM PAGELARAN WAYANG KULIT PURWA}

\section{Dewi Shinta}

Epos Ramayana menceritakan bahwa Sita (Shinta) bukan putri kandung Janaka. Suatu ketika Kerajaan Wideha dilanda kelaparan. Janaka sebagai raja melakukan upacara atau yadnya di suatu area ladang antara lain dengan cara membajak tanahnya. Ternyata mata bajak Janaka membentur sebuah peti yang berisi bayi perempuan. Bayi itu dipungutnya menjadi anak angkat dan dianggap sebagai titipan Pertiwi, dewi bumi dan kesuburan.

Sita dibesarkan di istana Mithila, ibu kota Wideha oleh Janaka dan Sunayana, permaisurinya. Setelah usianya menginjak dewasa, Janaka pun mengadakan sebuah sayembara untuk menemukan pasangan yang tepat bagi putrinya itu. Sayembara tersebut adalah membentangkan busur pusaka maha berat anugerah Dewa Siwa, yang pada akhirnya sayembara tersebut dimenangkan oleh Sri Rama, seorang pangeran dari Kerajaan Kosala. Setelah menikah, Sita pun tinggal bersama suaminya di Ayodhya, ibu kota Kosala.

Perjalanan kehidupan Dewi Sita ternyata tidaklah mulus, dikarenakan dirinya harus mengikuti suaminya yang menjalani masa pengembaraan di hutan dengan adiknya Lesmana. Dalam masa pengembaraan itulah kisah penculikan terhadap dirinya yang dilakukann oleh Rahwana terjadi hingga akhirnya terjadilah perang besar yang dikenal dengan nama perang Alengka antara Rahwana dan Sri Rama suaminya yang menuntut kembalinya Dewi Sita.

\section{Dewi Kunti}

Dewi Kunti dikenal sebagai ibu para Pandawa. Ketika bayi, Kunti diberi nama Perta oleh ayahnya yaitu Raja Surasena. Dewi Kunti memiliki seorang kakak lelaki yang bernama Basudewa yang merupakan 
ayah dari Kresna. Lalu Raja Kuntiboja (saudara sepupu Surasena) karena tidak memiliki keturunan mengadopsi Perta. Nama Perta, sejak diadopsi oleh Raja Kuntiboja, diganti menjadi Kunti.

Sebelum menikah dengan Pandu, Kunti memiliki seorang putra pemberian dari seorang dewa yang dipanggil oleh Kunti karena Kunti memiliki mantra sakti pemberian dari Resi Durwasa. Mantra ini bernama Adityahredaya yang dapat memanggil dewa-dewi. Ketika Kunti mencoba mantra ini sambil memandang matahari terbit, maka dewa Surya langsung datang kepada Kunti sehingga Kunti kaget dan menyuruh Dewa Surya untuk kembali. Dewa Surya, namun demikian, menyuruh Kunti untuk membuat keinginan apa saja sebelum ia kembali. Kunti tetap tidak menginginkan apa-apa, maka dewa Surya menjadikan Kunti mengandung. Setelah melahirkan, dewa Surya mengembalikan keperawanan Kunti dan lalu kembali ke Kahyangan.

Anak itu kelak diberi nama Karna dan karena Kunti tidak menginginkan anak, maka anak tersebut dihanyutkan ke sungai Aswa diberi ciri pakaian perang lengkap, anting-anting dan kalung pemberian Dewa Surya. Anak ini ditemukan oleh Adirat, seorang kusir keraton Hastinapura. Selanjutnya anak itu oleh Adirat diberi nama Basusena. Arti kata Karna adalah "telinga" dan ada juga arti "mahir atau terampil" dalam bahasa Sansekerta.

Selanjutnya Kunti menikah dengan raja Hastinapura yaitu Pandu setelah Pandu memenangkan sayembara Prabu Kuntiboja. Pandu lalu menikahi Madri, adik dari Salya dari Kerajaan Madra. Salya kalah tanding dengan Pandu, maka memberikan adiknya itu kepada Pandu. Pandu, namun demikian harus menanggung kutukan bahwa ia akan meninggal bila berhubungan suami istri, sehingga Pandu tidak memiliki keturunan dari kedua istrinya tersebut.

Pandu dan kedua istrinya, pada akhirnya meninggalkan kerajaan Hastinapura menuju hutan dan bertapa. Di hutan ini Kunti kembali menggunakan matra yang ia miliki untuk memanggil dewa dan dewi. Kunti memanggil Dewa Yama, Bayu, dan Indra maka ia memiliki tiga putera yaitu Yudistira, Bima, dan Arjuna. 
Kunti juga membantu Madri memanggil Dewa Aswin, maka Madri memiliki putera kembar bernama Nakula dan Sadewa. Kisah sedih terjadi pada Madri adalah ketika ia berhubungan suami istri dengan Pandu yang mengakibatkan Pandu meninggal dunia karena kutukan yang ada pada Pandu. Dan sebelum Madri menceburkan diri pada api kremasi untuk menyusul suaminya yaitu Pandu, Madri menitipkan anak kembarnya kepada Kunti agar menganggap Nakula dan Sadewa seperti anak sendiri.

\section{Srikandi}

Riwayat hidup Srikandi dikenal dalam dua versi, yang pertama adalah versi India yang mengatakan bahwa Srikandi adalah seorang laki-laki atau perempuan yang dibesarkan sebagaimana seorang lakilaki dan kemudian setelah dewasa Srikandi menikah dengan seorang wanita. Dikisahkan bahwa saat malam pertamanya, isteri Srikandi kaget mendapati suaminya sebenarnya adalah seorang perempuan dan kemudian dengan emosi marah dan menghina Srikandi habis-habisan hingga Srikandi merasa tersinggung dan malu kemudian berniat bunuh diri. Niat ini namun demikian berhasil dicegah dan Srikandi diselamatkan oleh seorang resi bernama Yaksa. Yaksa pun akhirnya berkenan bertukar kelamin dengan Srikandi, hingga Srikandi menjelma jadi seorang pria, dan kembali pada istrinya, hidup bahagia dan punya anak pula.

Masih pada versi ini, dalam sebuah pertempuran dengan Srikandi pada Bharatayuda, Bisma tersadar, bahwa sesungguhnya Srikandi adalah titisan/jelmaan Dewi Amba. Artinya, Srikandi adalah seorang wanita, dan Bisma pantang bertempur apalagi membunuh wanita. Maka dia pun menjatuhkan senjatanya, sementara Arjuna, yang berada di belakang Srikandi, langsung menggunakan kesempatan ini untuk menewaskan Bisma, dengan menembakkan panah penghancurnya.

Versi lain kisah hidup Srikandi dikisahkan dalam cerita pewayangan versi Jawa. Versi ini mengisahkan bahwa Srikandi lahir karena keinginan kedua orangtuanya, yaitu Prabu Drupada dan Dewi Ganda- 
wati, yang menginginkan kelahiran seorang anak secara normal dikarenakan kedua kakaknya Srikandi, yaitu Dewi Dropadi dan Drestadyumna, dilahirkan melalui puja semadi. Dropadi dilahirkan dari bara api pemujaan, sementara asap api itu menjelma menjadi Drestadyumna.

Srikandi sudah gemar dalam olah kanuragan/keprajuritan dan mahir bermain senjata, di mana ilmu ini diperolehnya dari Arjuna. Tak hanya menularkan kepiawaiannya bermain senjata dan olah kanuragan, ternyata kebersamaan Srikandi dan Arjuna menumbuhkan benihbenih cinta. Arjuna pun akhirnya menikahi Srikandi dan memperoleh seorang putra.

Srikandi menjadi suri tauladan prajurit wanita karena Srikandi adalah perempuan yang sakti. Ia bertindak sebagai penanggung jawab keselamatan dan keamanan kesatrian Madukara dengan segala isinya. Dalam perang Bharatayuda, Srikandi tampil sebagai senapati perang Pandawa menggantikan Resi Seta, ksatria Wirata yang telah gugur untuk menghadapi Bisma, senapati agung balatentara Korawa. Srikandi, dengan panah Hrusangkali, dapat menewaskan Bisma, sesuai kutukan Dewi Amba, puteri Prabu Darmahambara, raja negara Giyantipura, yang dendam kepada Bisma.

Akhir riwayat Srikandi, diceritakan bahwa Srikandi tewas dibunuh oleh Aswatama yang menyelundup masuk ke keraton Hastinapura setelah berakhirnya perang Bharatayudha.

Dua versi yang mengisahkan perjalanan hidup Srikandi, baik versi Jawa maupun versi India, keduanya mengisahkan bahwa Srikandi adalah seorang wanita dengan karakter yang berwibawa, bijaksana, bertanggung jawab dan pantang menyerah dalam membela kebenaran.

Dari situlah kemudian, kata 'Srikandi' jadi membudaya. Menjadi familiar dan sering dipergunakan sebagai ungkapan terhadap seorang wanita yang heroik, penuh semangat dan pantang menyerah dalam mengupayakan sebuah kemajuan dan menebar manfaat. 


\section{NILAI-NILAI FEMINIS TOKOH PEREMPUAN DALAM PAGELARAN WAYANG KULIT PURWA (DEWI SHINTA, DEWI KUNTI DAN SRIKANDI)}

\section{Dewi Shinta}

Sebagai salah seorang tokoh wanita dalam pagelaran wayang kulit purwa yang diambil dari seri cerita Ramayana, Dewi Shinta memiliki peranan penting dalam berbagai lakon atau ceritanya selama perjalanan hidupnya, di antaranya: Pertama, Dewi Shinta adalah gambaran seorang isteri yang setia terhadap suaminya dalam suka maupun duka. Dikisahkan bahwa Dewi shinta adalah seorang puteri raja yang menjdi anak kesayangan ayahnya, sudah barang tentu Dewi Shinta tumbuh dan besar dalam suasana yang serba mewah dan berkecukupan. Mungkin dapat dikisahkan bahwa selama hidupnya Shinta selalu merasa senang, namun saat suaminya harus meninggalkan istana dan tinggal di hutan karena menjalani masa pembuangan, Dewi Shinta lebih memilih untuk meninggalkan kenikmatan dan kemewahan istana demi untuk mengikuti suaminya hidup sengsara di tengah hutan selama 14 tahun. Kondisi yang dialami Dewi Shinta pada saat itu tentu bukanlah kondisi yang mudah dan bisa dialami oleh setiap perempuan, Karena untuk melakukan hal tersebut diperlukan keteguhan hati dan dengan kesadaran penuh akan menghadapi bahaya dan banyak kesulitan ke depannya dalam mengarungi kehidupan rumah tangga dengan Rama.

Kondisi seperti tersebut sudah barang tentu merupakan suatu hal yang patut dijadikan nilai terpuji bagi seorang perempuan. Di saat banyak perempuan yang hanya menuntut fasilitas dan kemewahan, sikap Shinta menunjukkan bahwa sebagai seorang isteri, dirinya akan setia mendampingi suaminya dalam suka maupun duka. Sikap Shinta yang demikian sudah barang tentu tidak dapat dilaksanakan dengan sempurna. Di sisi lain jiwa kewanitaan Shinta yang menginginkan sesuatu yang mewakili nilai keindahan dan kemewahan (Kijang Kencana) tidak bisa dihindari. Justru dalam hal ini dikisahkan bahwa 
keinginan Shinta yang berada dalam kapasitas "ego" nya tersebut pada akhirnya membawa mala petaka besar, yaitu perang Alengka.

Kedua, Shinta adalah sosok wanita setia dan tahan terhadap godaan serta berpendirian teguh. Cerita Ramayana mengisahkan bahwa dalam penyekapannya (penculikannya yang dilakukan oleh Rahwana), Shinta tergolong sebagai perempuan yang setia dan teguh pada pendiriannya. Meskipun Shinta hidup dalam penyekapan Rahwana selama bertahun-tahun, namun dirinya dapat menjaga kesuciannya dengan ancaman bahwa dirinya akan bunuh diri menggunakan cundrik-nya jika Rahwana memaksakan kehendaknya. Dalam kondisi di dalam penyekapan itulah Shinta mendapatkan kesadaran bahwa keinginannya untuk mendapatkan Kijang Kencana membuahkan malapetaka bagi semua orang di Alengka. Kemudian Shinta bertekat untuk akan terus menjalani perjalanan hidupnya dengan penuh keikhlasan untuk menebus dosanya.

Kesadaran Dewi Sinta membuka selubung hijab, aku ini siapa? Untuk apa aku di dunia? Apakah ada rencana besar Hyang Widhi untuk melenyapkan keangkaramurkaan, atau untuk melenyapkan etnis raksasa, perpaduan antara manusia dan binatang? Dia telah mendapat peran yang harus dijalankannya dengan baik. Dewi Sinta sadar dirinya terlibat kepada Hukum Sebab-Akibat, dan dia akan menjalaninya dengan penuh kesadaran. Kemudian Dewi Sinta memahami adanya Hukum Evolusi, termasuk evolusi dalam kesadaran. Keputusannya sudah bulat semua akan dilakoninya dengan penuh kesadaran.

Ketiga, Shinta adalah sosok wanita yang religious. Ramayana menceritakan bahwa dalam keadaan no-mind, Shinta pasrah kepada Tuhan yang Maha Kuasa. Ketika Rahwana beserta balatentaranya berhasil dihancurkan pasukan Sri Rama. Dan, ketika Sri Rama tidak mau menjajah negara Alengka dengan menyerahkan tampuk pimpinan kerajaan Alengka kepada Wibisana adik Rahwana, Dewi Shinta semakin bersyukur kepada Tuhan dikarenakan dirinya dikaruniai suami yang bijaksana. Kebahagiaan bersatu kembali dengan Sri Rama pun dijalani dengan penuh kesadaran. . Bahkan ketika Sri Rama mengikuti 
pendapat penduduk negaranya untuk tes uji kesucian bagi dirinya, DewiSinta menerima dengan penuh kesadaran.

Shinta berpandangan bahwa dirinya telah melakukan banyak hal yang buruk yang pada akhirnya menyebabkan kesengsaraan banyak makhluk hidup di muka bumi. Maka apabila Hyang Widhi pada akhirnya akan mengambilnya dalam api upacara yang membakar dirinya hidup hidup, dirinyapun akan menerima dengan tegar dan pasrah. Hingga pada akhirnya seluruh negeri terkesima dengan selamatnya Dewi Sinta dari amukan api. Seluruh negeri menerima kembali Dewi Sinta sebagai permaisuri dari Sri Rama. Seseorang yang menyadari hakikat kehidupan, bahwa hidup di dunia ini terikat dengan hukumhukum alam maka dia akan dapat menerima kejadian apa pun yang menimpanya. Perjuangan meningkatkan kesadaran tak pernah berhenti. Karena hidup di alam dan bahan bakunya dari alam, maka seseorang memang tidak bisa melepaskan diri dari alam. Tetapi alam akan membantu seseorang yang serius mendarmabaktikan dirinya bagi alam.

Keempat, Dewi Sinta mengasingkan diri demi keutuhan kerajaan Ayodya. Perjalanan kehidupan seseorang mempunyai alur-alur baru yang sering diluar nalarnya. Setelah mengalami kebahagiaan bersama Sri Rama menjadi permaisuri di kerajaan Ayodya, dia masih saja mendengar banyaknya suara-suara penduduk yang tetap menyangsikan kesuciannya walau dia sudah selamat dibakar di atas api. Sri Rama adalah raja besar yang bijaksana, dan juga seorang suami yang baik. Tetapi sebagai seorang raja, Sri Rama sudah seharusnya lebih mementingkan kepentingan negara daripada kepentingan pribadi. Dewi Sinta adalah seorang istri yang luar biasa baiknya, tetapi dia lebih mementingkan negara dari pada kepentingan pribadinya. Demi negara, demi suami tercinta, pada malam hari dia menyelinap ke luar istana pergi jauh meninggalkan istana. Setelah itu dia seakan lenyap ditelan rimba. Hanya berbekal keyakinan kepada Hyang Widhi, dia merelakan segala-galanya 


\section{Dewi Kunti}

Dewi Kunthi adalah penggambaran sejati perjalanan seorang ibu yang mendidik dan melahirkan putera-putera yang hebat seperti Pandawa. Perjalanan spiritual seorang ibu dimulai saat dirinya mempersiapkan jiwa dan raganya agar indung telurnya dibuahi. Selanjutnya indung telur yang berubah menjadi sel induk dipelihara dalam rahim yang kokoh nan lembut untuk difasilitasi bagi perkembangan janin dan dibawa kemanapun juga selama sembilan bulan sepuluh hari. Setelah sang bayi lahir, diberinya sang anak makanan dari air susunya, diajarinya bicara dengan penuh kesabaran, bahkan terus-menerus didoakannya sampai akhir hayat dirinya. Demikianlah kasih seorang ibu.

Perjalanan hidup Dewi Kunti dikisahkan saat dalam peristiwa pembakaran istana kayu di Waranawata, Kunti bersama Pandawa selamat dari kobaran api dan melanjutkan pengembaraan di hutan. Saat mereka sampai di daerah negeri Eka Chakra, mereka mendengar ada raksasa serakah Bakasura yang setiap hari minta disediakan makanan lembu se-gerobak penuh dan dua buah kerbau. Setelah beberapa lama bahkan pengantarnya pun disantapnya. Ketika masyarakat bingung siapa yang akan mengantar makanan hari itu, Dewi Kunti mengatakan agar anaknya Bhima yang akan melakukannya. Hanya seorang ibu yang percaya kepada anaknya dan juga penuh kasih terhadap sesama yang dapat melakukan hal demikian. Raksasa Bakasura akhirnya mati dibunuh oleh Bhima.

Kunti juga menggambarkan kesetiaan seorang isteri yang rela mengikuti karma suaminya dan hidup di tengah hutan belantara. Kunti menggunakan ilmu yang dia miliki untuk memanggil dewa guna mendapatkan putera. Kunti sadar bahwa keturunan Pandhu adalah keharusan bagi dinasti Bharata. Kunti juga menggunakan ilmunya untuk isteri Pandu yang lain sehingga lahirlah si kembar Nakula Sadewa. Kepatuhan dan pengabdiannya pada suami dan anak-anak merupakan nilai feminis yang coba diajarkan melalui sosok seorang Dewi Kunti. 


\section{Dewi Srikandi}

Dalam Serat Candrarini ia digambarkan sebagai putri raja yang cantik, parasnya bagai bulan, kulitnya bak emas sinangling/digosok, lirikan matanya galak-galak manis, tubuhnya sintal, badannya tinggi semampai. Tutur katanya lepas, gerak gayanya pantas, luwes, memikat, halus budinya. Pandai melayani suami, pandai menyelaraskan busana sesuai dengan waktu dan tempat, menjadi teladan para wanita. Terhadap para madunya sikapnya bersaudara, tidak mudah terpengaruh oleh omongan yang digelar. Ia supel tidak jadi marah, hilang marahnya menjadi sayang, Ia sangat gemar membaca kitab wulang dengan suaranya yang merdu mengalunkan tembang Wisatikandeh. Meskipun sangat disayang Arjuna ia tidak menjadi sombong, sebagai balasannya ia sangat hormat dan bakti dan sayang kepada mertua, Dewi Kunti, dengan setiap hari ada saja yang dikirimkannya, dan semua keinginan dewi Kunti dipenuhi. Watak yang demikian ini, mengutamakan kebaikan dan senang menuntut ilmu dengan membaca kitab-kitab wulang menunjukkan watak ksatria, sesuai dengan darah yang mengalir di tubuhnya, sebagai putri raja.

Srikandi, nama itu tak asing di telinga orang indonesia sehingga menjadi icon sebuah kekuatan tentang wanita yang tangguh. Hampir setiap pergolakan dan pergerakan atas nama wanita, nama Srikandi ini muncul dan menjadi simbol kekuatan sebuah tokoh wanita. Kisah perjalanan hidup Srikandi memang memiliki banyak versi, namun dari semuanya terdapat satu kesamaan yaitu tentang keberaniannya dan sikapnya yang menginginkan bahwa wanita tidak harus lemah di hadapan pria.

Srikandi, dalam perang Bharatayudha, menjadi 'sesepuh' dan 'tuladha' bagi kebanyakan prajurit wanita yang ada. Setiap pergerakannya dicontoh oleh wanita lainnya, Srikandi juga bertindak sebagai penanggung jawab keselamatan dan keamanan kesatrian Madukara dengan segala isinya. Kisah peperangan yang memenangkan Pandawa atas Kurawa juga tidak lepas dari usaha Srikandi dalam peperangan, yaitu setelah Bisma dapat disingkirkan dari perang Kurusetra, yang berdampak besar pada perubahan strategi dan semangat kesatria Kurawa. 
Srikandi juga merupakan simbol bahwa seorang perempuan tidak harus hanya duduk berdiam diri tanpa melakukan sesuatu yang berharga bagi negaranya. Srikandi adalah contoh nyata bahwa perempuan juga berhak dan pantas untuk menuntut ilmu dan melakukan aksi nyata bagi negaranya.

\section{RELEVANSI NILAI FEMINIS \\ DALAM PAGELARAN WAYANG KULIT PURWA BAGI KEHIDUPAN PEREMPUAN JAWA}

Budaya Jawa juga sering menempatkan perempuan seolah-olah menjadi nomor dua. Perempuan Jawa tidak ditempatkan pada kedudukan yang setara dengan laki-laki. Namun demikian perempuan tetap memberikan sifat-sifat atau ciri yang terhormat, antara lain kesetiaan, kepatuhan, kesabaran, dan kemampuan untuk menyembunyikan gejolak batin. Sederet ciri atau sifat kebaikan itu bukan hanya diberikan kepada tokoh perempuan dari kalangan ningrat saja tetapi juga kepada mereka yang berasal dari kalangan rakyat jelata (Sarjono, 1992: 45).

Perempuan Jawa yang masih keturunan ningrat selalu berusaha menempatkan kebahagiaan pada kehidupan perkawinannya. Dapat dikatakan, hal ini semacam identifikasi diri dengan suaminya, bahkan semacam peleburan diri. Kebahagiaan suami adalah kebahagiaan dirinya. Sedemikian kuatnya anggapan itu sehingga semua istri dari golongan priyayi selalu berusaha sekuat tenaga untuk membahagiakan suami dengan berbagai cara (Sarjono, 1992: 49). Hal tersebut tentu saja juga terjadi dalam kehidupan seksualitas, yaitu ketika pihak perempuan selalu mengalah dan menjadi nomor dua untuk membahagiakan pasangannya.

Perempuan Jawa dalam kehidupannya, terbiasa dengan didikan untuk selalu mengalah. Kehidupan rumah tangga seorang istri tidak mungkin bisa memiliki suaminya secara penuh. Perempuan Jawa dalam kehidupan kesehariannya selalu ditempatkan dalam kehidupan yang tidak setara dengan kaum pria namun memberi sifat atau ciri-ciri yang terhormat kepada mereka dengan sederet kebaikan, antara lain, 
kesetiaan, kepatuhan, kesabaran, kemampuan untuk menyembunyikan gejolak batin dan semacam itu. Sederet ciri atau sifat kebaikan itu diberikan bukan hanya kepada tokoh perempuan dalam kalangan ningrat saja, tetapi juga kepada perempuan-perempuan yang berasal dari golongan rakyat jelata (Sarjono, 1992:45).

Perempuan Jawa adalah perempuan yang dalam kehidupan sehari-hari mengikuti adat istiadat dan kebudayaan Jawa (MagnisSuseno, 1993: 3). Kehidupan perempuan di Indonesia khususnya Jawa banyak dipengaruhi oleh budaya yang memang sudah melekat dalam kehidupannya khususnya budaya wayang. Seluruh sendi kehidupan memang tanpa disadari banyak dipengaruhi oleh cerita dan kisahkisah dalam pewayangan. Salah satunya adalah tentang para wanita Jawa yang belajar untuk menjadi wanita yang baik melalui sosok dan figur dalam lakon-lakon pergelaran wayang kulit.

Menurut adat Jawa, seorang isteri yang ideal harus memiliki sikap seperti yang dikisahkan dalam sosok Dewi Kunti maupun Dewi Shinta yang harus berbakti kepada suami, rela menerima kondisi suami apa adanya dan rela ikut dalam kondisi yang tidak menyenangkan, sabar setia sederhana, patuh, taat, dan terampil seperti Dewi Kunti (Darweni, 1994)

Wayang sebagai budaya lokal bagi masyarakat Jawa sudah barang tentu membawa nilai-nilai dan sifat-sifat yang banyak dianut serta mempengaruhi kehidupan manusia di Jawa tak terkecuali kehidupan perempuan Jawa.

Sifat yang menempel dalam kehidupan masyarakat Jawa yang sesuai dengan ajaran wayang yaitu seorang perempuan menurut adat Jawa juga harus cerdik dan terampil seperti Srikandi dan rela maju membela suami saat sedang dibutuhkan atau dengan kata lain dalam kehidupannya perempuan Jawa harus:

1. Mempunyai sikap menyerahkan diri pada suami

2. Mempunyai sikap terampil dan cakap.

3. Memiliki sifat religius dan pasrah pada takdir Yang Maha Kuasa.

Hal tersebut juga sejalan dengan ajaran filosofis dalam upacara adat pernikahan di Jawa, bahwa seorang isteri harus mencuci kaki sua- 
minya, dengan ajaran bahwa seorang isteri harus selalu menjaga kehormatan suaminya dan membersihkan nama baik suaminya apabila suami salah melangkah. Hal ini sejalan dengan yang dilakukan oleh Srikandi yang bersedia maju berperang melawan resi Bisma saat suami dan negaranya membutuhkannya.

\section{SIMPULAN}

Kesimpulan yang dapat diambil dari penelitian ini adalah bahwa pagelaran wayang kulit purwa adalah suatu karya seni fenomenal yang memiliki kisah-kisah yang dapat dijadikan gambaran bagi kehidupan manusia. Sifat-sifat yang digambarkan dalam karakter wayang kulit purwa juga merupakan gambaran karakter-karakter manusia di dunia. Demikian juga gambaran sifat dan kehidupan tokoh-tokoh perempuan dalam pergelaran wayang kulit.

Nilai-nilai feminisme yang diajarkan dalam pergelaran wayang kulit di antaranya adalah bahwa perempuan dalam wayang yang digambarkan dalam tokoh Dewi Shinta, Srikandi dan Dewi Kunti adalah sikap bakti dan hormat pada suami baik dalam suka maupun duka, setia dan taat pada suami, selalu menjaga kesucian, religius, dan terampil membela suami dalam kesulitan.

Nilai-nilai feminisme yang diajarkan dalam pergelaran wayang kulit purwa tersebut banyak digunakan sebagai ajaran dalam kehidupan perempuan di jawa yang memegang teguh nilai-nilai kesetiaan terhadap suami dan sabar dan ikhlas menjalani hidup dan kehidupan.

\section{DAFTAR PUSTAKA}

Darweni, 1994, Serat Wulang Reh Putri, Rekso Pustoko, Istana Mangkunegaran, Surakarta.

Faqih, Mansour, 1987, Analisis Gender dan Transformasi Sosial, Pustaka Pelajar, Yogyakarta.

Murata, Sachiko, 1999, The Tao of Islam, Mizan, Bandung.

Notonagoro, 1968, Pancasila Secara Ilmiah Populer, Fakultas Filsafat Universitas Gadjah Mada, Yogyakarta. 
290 Jurnal Filsafat, Vol. 26, No. 2, Agustus 2016

Sarjono, M. A, 1992, Paham Jawa: Menguak Falsafah Hidup Manusia Jawa Lewat Karya Fiksi Mutahir Indonesia, Pustaka Sinar Harapan, Jakarta.

Supadjar, Damardjati, 1993, Nawangsari, MW Mandala, Yogyakarta.

Sutrisno, Sulastin et al., 1985, Bahasa, Sastra, Budaya, Gadjah Mada University Press, Yogyakarta.

Magnis-Suseno, Franz, 1993, Etika Jawa, Gramedia, Jakarta. 